\title{
É Possível Conciliar Educação com Trabalho Infantil?*
}

\author{
WILLIAM E. MYERS \\ University of California, Davis \\ wemyers@mother.com
}

\begin{abstract}
Resumo
Na maioria dos países, as leis sobre ensino obrigatório e trabalho do menor refletem a idéia de que o estudo e a participação econômica da criança são incompatíveis e que, portanto, as crianças em idade escolar devem ser obrigadas a freqüentar a escola e proibidas de trabalhar. No entanto, uma política diferente, que busca conciliar trabalho infantil com a educação, de forma que as crianças possam acomodar ambos em sua vida, pode, em última análise, ser mais benéfica a elas e à sociedade. O fato de haver, na prática, vários modelos para se combinar educação com trabalho sugere que essa política pode ser implementada com sucesso.
\end{abstract}

Palavras-chave: crianças trabalhadoras, trabalho infantil, legislação sobre idade mínima, ensino obrigatório, educação e trabalho.

\section{Resumen}

En la mayoría de los países, las leyes sobre la obligatoriedad de la enseñanza y el trabajo del menor reflejan la idea de que el estudio y la participación económica del niño son incompatibles y que por eso, los niños en edad escolar deben ser obligados a frecuentar el colegio y prohibidos de trabajar. En contrapartida, una política diferente, que busca conciliar trabajo infantil y educación, de tal forma que los niños puedan ajustar a ambos en sus vidas, puede, en ultima análisis, ser más benéfica a ellos y a la sociedad. En la práctica, el hecho de haber varios modelos que integren educación y trabajo sugiere que esa política puede ser aplicada con suceso.

Palavras-clave: niños trabajadores, trabajo infantil, legislación sobre mínima edad, enseñanza obligatoria, educación y trabajo.

\begin{abstract}
In most countries, child labor and compulsory education laws reflect the idea that education and children's economic participation are incompatible, and that school-aged children should therefore be obliged to attend school and prohibited from engaging in work. However, a different policy, one seeking to reconcile children's work and education so that children can fit both into their lives, may ultimately be more beneficial for children and

* Este artigo foi publicado originalmente em inglês no International Journal of Educational Policy, Research and Practice, v.2, n.3, p. 307-330, Autumm 2001. Traduzido e publicado com autorização do IJEPRP e do autor.

Tradução: Maria Lúcia Mendes Gomes e Vera Luiza Visockis Macedo. E-mail: unitrad@unitrad.com.br.
\end{abstract}


society. The fact that various models for combining education and work are available in practice suggests that such a policy can be successfully implemented.

Key words: working children, child labor, minimum age laws, compulsory education, education and work. 
Nos últimos anos, a relação entre educação e trabalho infantil voltou a ser objeto de interesse e de intensos debates. O novo interesse provém do renascimento da preocupação internacional com relação ao trabalho infantil, em especial nos países em desenvolvimento, e com a permanência da antiga crença de que a escola é a atividade mais apropriada à infância e o ensino obrigatório um antídoto contra a exploração econômica das crianças. Tanto o público em geral como os formuladores de políticas educacionais conservam a premissa tradicional de que a freqüência à escola e o trabalho infantil, que vá além de tarefas rotineiras leves, são incompatíveis. Dessa forma, as normas internacionais, notadamente a Convenção sobre Idade Mínima (n.138), adotada em 1973 pela Organização Internacional do Trabalho - OIT -, e as políticas nacionais para controle do trabalho do menor têm, desde o século XIX, dado ênfase à proibição da participação econômica das crianças até que alcancem a idade em que não são mais obrigadas por lei a freqüentar a escola (Bequele, Myers, 1995). No arcabouço dessa política, um objetivo importante do ensino obrigatório é manter as crianças fora do mercado de trabalho até a idade legal de admissão em emprego, normalmente estabelecida nos meados da adolescência.

A intensificação do debate aconteceu porque novas pesquisas e opiniões desafiaram o pressuposto da incompatibilidade entre trabalho e estudo e questionaram a sabedoria transmitida com relação à eficácia e propriedade da legislação sobre o trabalho do menor para reduzir a ocorrência de trabalho infantil (Boyden 1994; Boyden, Ling, Myers, 1998; Myers 1999). Esse debate é ao mesmo tempo técnico e político, e embora transcenda os limites deste artigo registrar suas inúmeras complexidades, pode-se de relance perceber sua importância no caso da Índia. A Índia sofre as conseqüências de um dos mais baixos índices de alfabetização, de freqüência à escola e de conclusão do ensino fundamental e um de seus maiores desafios, para o desenvolvimento social e econômico, é a superação do déficit educacional, particularmente o feminino e nas áreas rurais. Acredita-se também, de maneira geral, haver na Índia mais crianças em idade escolar e que trabalham do que em qualquer outro país. Em 1991, Myron Weiner, professor de Ciência Política no Massachusetts Institute of Technology, publicou um estudo, um clássico na atualidade, em que ele vinculava esses dois problemas. Ele afirmava que o trabalho infantil e a educação escolar são mutuamente incompatíveis, e que o baixo nível de alfabetização e educação da Índia são produto dos altos índices de trabalho infantil que, por sua vez, resultam da ampla aceitação social do trabalho das crianças, quando deveriam estar estudando. Weiner afirmava que o trabalho infantil só poderia ser abolido e as crianças educadas de forma adequada por meio do cumprimento rigoroso de leis rígidas de ensino 
obrigatório. Em outras palavras, um dos objetivos principais da educação deveria ser a erradicação do trabalho infantil que, na opinião dele, poderia ser alcançada com maior eficácia por meio de leis de ensino obrigatório do que por intermédio de legislação sobre o trabalho do menor que visasse o local de trabalho. Examinando a situação fora da Índia, Weiner defendia seu argumento afirmando que o progresso no ocidente ligava-se historicamente à erradicação do trabalho infantil, alcançado em grande parte pelo ensino obrigatório. Seu livro atraiu a atenção geral e reforçou a idéia, prevalecente entre muitos formuladores de políticas e educadores, de que o trabalho na infância, quase que inevitavelmente, diminui a participação e o desempenho educacionais.

Os especialistas tendem a duvidar dos argumentos de Weiner, que consideram simplistas e sujeitos a muitas críticas: o problema é a pobreza, muito mais do que a cultura (Krishna, 1996; Lieten, 1999, 2000). Embora o trabalho em tempo integral possa realmente impedir a educação efetiva das crianças, a maioria das que trabalham mora em áreas rurais onde costumeiramente trabalham parte do tempo e podem ainda freqüentar, pelo menos, a escola primária (Nieuwenhuys, 1994). Para muitas crianças, não há escolas disponíveis nas proximidades ou não conseguem ter acesso a elas. Quase sempre, as instalações e a metodologia de ensino nas escolas são precárias demais para ser eficazes e os professores, muitas vezes, maltratam ou desencorajam as crianças das castas mais pobres (Krishna, 1996). Nos países industrializados, o ensino obrigatório, embora importante, não desempenhou o papel único e fundamental na erradicação do trabalho infantil que Weiner lhe atribui; historiadores econômicos e sociais (Cunningham, 1991, 2000; Nardinelli, 1990) tendem a apoiar outras explicações mais complexas.

A tese de Weiner não se sustenta quando comparada com os dados relativos à Índia neste particular. Por exemplo, cotejando os onze estados da Índia onde há maior incidência de crianças trabalhadoras, Krishna (1996) verificou que os índices estaduais de trabalho infantil praticamente não tinham relação com a matrícula na escola nem com os índices de conclusão do curso. Os estados nos quais havia maior número de crianças trabalhadoras não eram, predominantemente, os piores colocados na escala de freqüência à escola e desempenho, e os estados com maiores índices de participação e conclusão do curso não eram, como seria de se esperar, aqueles em que havia menor número de crianças trabalhadoras. Descobriu-se ainda que muitas crianças que trabalham abandonam a escola mais por desalento, com relação à má qualidade do ensino e às precárias condições da escola local disponível, do que pela necessidade de trabalhar, indicando que a escola pode ser tanto parte do problema como da solução. Se lhes for dada a oportunidade, com 
programas educativos não formais e inovadores, algumas crianças logram combinar trabalho e estudo com sucesso. Em outros casos, a retirada da criança do trabalho realmente trouxe resultados benéficos na participação e no desempenho escolar. Em resumo, Krishna e outros (Lieten, 1999; Nieuwenhuys, 1994) perceberam que a realidade é mais sutil e diversificada do que Weiner sugeria. Eles concluíram que, embora esse possa ser um dos fatores, o trabalho infantil e o analfabetismo, na Índia, não são conseqüência apenas da aceitação cultural do trabalho do menor. Será necessário muito mais do que leis sobre ensino obrigatório para combater as raízes do problema, cravadas na pobreza e injustiça social para, por fim, erradicá-los. Todavia, as idéias de Weiner ainda contam com defensores entusiastas. O debate sobre trabalho e educação infantil, bem como se as políticas educacionais nacionais devem ou não procurar inibir o trabalho infantil, continua a gerar polêmica na Índia, da mesma forma que no restante da Ásia, África, América Latina e em outros lugares. Lá, como na maior parte do mundo, o discurso que dá ênfase ao conflito entre trabalho e educação infantil orienta as políticas relacionadas com o trabalho do menor e as políticas educacionais.

Esse discurso pode não prestar um bom serviço à causa infantil. Alguns temem que políticas rígidas, que separem o trabalho do estudo, não se coadunem com o entendimento moderno sobre o desenvolvimento da criança e de que essas políticas sejam, por si só, um obstáculo que impede muitas delas - em especial as mais pobres - de conseguir a educação de que necessitam (Boyden, 1994; Boyden, Ling, Myers, 1998). Conseqüentemente, muitos defensores e organizações não-governamentais que promovem os direitos e o bem-estar das crianças, alguns governos e um número crescente de educadores adotam um discurso muito diferente, o qual considera o trabalho como potencialmente formador e concilia a necessidade ou o desejo de trabalhar das crianças com seu direito de receber educação satisfatória. No entanto, essa perspectiva que destaca as possíveis ligações entre trabalho e educação não é tão conhecida da maioria dos educadores e formuladores de políticas como o é o ponto de vista que destaca o conflito entre essas duas atividades.

A proposta deste artigo é de ajudar a preencher tal falta de informação, desenvolvendo brevemente essa linha de pensamento e suas implicações e aplicações práticas. O objetivo é informar e sintetizar, e não analisar e, tendo de cobrir tópicos ainda não suficientemente desenvolvidos na literatura, em alguns casos tomará como base a experiência do autor. A discussão se inicia com história recente, ilustrando como a conexão entre trabalho e educação apareceu nas políticas educacionais internacionais e indicando que a adoção de formas que conciliam o trabalho com a educação surgiu com aval de qualidade e alto 
grau de legitimidade. Em seguida, discutem-se as diferentes formas de combinar trabalho e educação, fornecendo uma tipologia que separa os modelos conforme suas finalidades. E termina com algumas observações a título de conclusão.

\section{O INTERESSE DAS POLÍTICAS INTERNACIONAIS EM COMBINAR EDUCAÇÃO E TRABALHO}

Durante as décadas de 1970 e 1980, a idéia de propiciar trabalho e educação no desenvolvimento das crianças e jovens era bem aceita por muitos especialistas, pelos mais importantes órgãos internacionais, como a Unesco, a OIT e a Unicef, e por várias organizações não-governamentais que promoviam a reforma da educação. Eles achavam que equilibrar o aprendizado escolar das crianças com trabalho produtivo melhoraria o ensino, e não o prejudicaria. $\mathrm{O}$ entusiasmo devia-se não apenas por tornar realisticamente compatível o ensino e o trabalho no dia-a-dia das crianças, mas também por explorar o valor do trabalho como veículo de aprendizagem em si mesmo. Foi amplamente demonstrado que crianças e jovens tendiam a aprender com mais facilidade certas habilidades e atitudes essenciais da vida por meio do trabalho produtivo do que na sala de aula. Por exemplo, em folheto intitulado A Educação pelo trabalho, um eminente educador brasileiro, seguidor dos conceitos de Paulo Freire, observou que a vantagem do trabalho como ferramenta educacional consiste em que as crianças aprendem mais no curso dos acontecimentos do que por meio de palavras (Costa, 1984). Prosseguindo com o exemplo do Brasil, o governo e a Unicef documentaram e publicaram, em conjunto, um relato tecendo comentários elogiosos sobre vários programas inovadores, com base na comunidade, que estruturavam o trabalho produtivo como uma valiosa experiência de aprendizado e fonte de renda segura para crianças desfavorecidas que, caso contrário, se envolveriam em atividades potencialmente perigosas, como vendedor de rua (Ministério da Previdência e Assistência Social, Unicef, 1983). Embora preocupado com as implicações de longo prazo das políticas ao estabelecer facilidades educacionais distintas para pobres e ricos, o Ministério da Educação via esses programas com bons olhos, como fontes de inspiração e desafio para a reforma de um sistema de educação formal fossilizado (Myers, 1988). Atitudes como essa eram comuns entre os educadores progressistas de muitos países da África, Ásia e América Latina. 


\section{A década de 1970}

No fim dos anos 70 e início da década de 1980, a Unesco examinou maneiras de vincular a educação ao trabalho infantil nos programas e políticas educacionais. Ela patrocinou três conferências regionais, encomendou um estudo condensando a experiência internacional e realizou a International Meeting of Experts on the Promotion of Productive Work in Education (Reunião Internacional de Especialistas na Promoção do Trabalho Produtivo na Educação), em Paris, de 24 a 28 de novembro de 1980. Mais ainda, a questão de como relacionar o trabalho com a educação primária e secundária estava na agenda da Conferência Internacional sobre Educação, da Unesco, de 1981. O relatório daquela conferência recomendava o fortalecimento da relação entre trabalho e educação.

Deve haver interação efetiva e constante entre educação e trabalho produtivo, no sentido de produção de bens e serviços materiais e intelectuais que são úteis ao indivíduo ou à sociedade, não necessariamente em troca de remuneração, $e$ levando em conta a contribuição do treinamento do próprio setor produtivo. Os esforços para estabelecer essa interação devem-se relacionar, como apropriado, com todos os níveis de educação e, embora permitindo uma certa independência dos elementos que a compõem, devem ressaltar a interdependência entre teoria e prática, o lugar e a importância do trabalho produtivo dentro da estrutura dos valores sociais, estéticos, culturais, econômicos e individuais e a melhor educação geral e profissionalizante possível. (Unesco, 1981, p. 28)

A documentação preliminar da Conferência Internacional sobre Educação de 1981 (Unesco, 1981) revela que os ministros da educação de todo o mundo acompanhavam a questão com considerável interesse e esperavam que a introdução do trabalho produtivo como atividade relacionada com a escola elevaria a contribuição econômica da educação e a tornaria democrática. Dependendo da situação, finalidade ou da faixa etária a que se destinava, isso poderia ser conseguido incorporando-se o trabalho produtivo nos programas e instituições educacionais ou levando a educação para o local de trabalho por meio de serviços de extensão educacional.

Documentos da Unesco daquela época $(1980,1981)$ dão relevância à dignidade do trabalho manual e intelectual e ao papel fundamental do trabalho na formação social e econômica de crianças e adultos. Eles mostram que, já em 1973, a Conferência Internacional sobre Educação havia observado que o trabalho produtivo deveria ser visto como parte do processo educativo global e deveria estar presente, alternando-se períodos de estudo e trabalho e em atividades produtivas na escola. Vale lembrar que 1973 foi o ano em que a OIT adotou a Convenção sobre Idade Mínima 
(n.138), que em seu artigo 6 desobriga explicitamente da proibição da convenção sobre idade mínima os estudantes que exercem trabalho como parte de sua formação.

Os ministros da educação pensavam, é evidente, que o trabalho produtivo deveria ser parte do ensino proporcionado a todas as crianças, não apenas aos pobres. Os ministros africanos, em reunião regional em 1976, disseram que a educação deveria ter por base o trabalho e ser planejada em termos dos requisitos do trabalho. Eles esperavam que isso ajudasse a derrubar as barreiras do preconceito entre trabalho manual e intelectual, teoria e prática, cidade e campo. Os ministros latinoamericanos, em 1979, também esperavam acabar com a discriminação entre trabalho manual e intelectual e viam o trabalho como meio de promover o desenvolvimento social e individual. Os ministros europeus apontavam uma distinção "absurda" entre escolas técnicas e profissionalizantes e os estabelecimentos acadêmicos em geral. Eles achavam que essa dicotomia anacrônica devia ser eliminada porque o aprendizado das habilidades manuais e não manuais era igualmente necessário. Especialistas asiáticos reunidos em seminário regional sobre educação técnica e profissionalizante, em 1979, observavam que atividades produtivas deveriam ser parte essencial do processo de aprendizagem geral dos estudantes e, conseqüentemente, serem incorporadas à educação das crianças desde cedo.

\section{A década de 1980}

Conforme texto preliminar da Unesco para a Conferência Internacional sobre Educação, de 1981, pesquisas indicaram que

a introdução do trabalho produtivo no currículo acadêmico tem por objetivo, em primeiro lugar e principalmente, ajudar a tornar os sistemas educacionais mais relevantes para as necessidades econômicas. A preocupação primordial é a de minorar as limitações impostas pela situação econômica e garantir que o ensino seja organizado de modo a tornar-se meio eficaz para obtenção de emprego. (Unesco, 1980, p. 11)

Mas o documento também observa que, na maioria dos programas experimentais que ligam o trabalho à produção,

a introdução do trabalho nos currículos escolares baseia-se na convicção de que tal fato originará novas atitudes e modificará os sistemas de valores das crianças por meio da ênfase na dignidade e valor do trabalho. Espera-se ainda reduzir a distinção entre o conhecer e o saber fazer, colocando-se imediatamente em prática 
o conhecimento teórico adquirido pelos estudantes. O trabalho produtivo deve encorajar o uso de experiências de aprendizagem paralelas, obtidas fora das instituições educacionais, e a integração do aprendizado formal e informal. (Unesco, 1980, p 14)

Considerava-se, assim, que a idéia de introduzir o trabalho produtivo no processo de ensino formal (para crianças e jovens) ou a educação no ambiente de trabalho (para adultos) seria um avanço educacional para todos, não apenas para os pobres. Educadores europeus e norte-americanos exploraram o trabalho aplicado como parte do currículo regular, normalmente por meio de trabalho supervisionado no nível da escola secundária. Nos países em desenvolvimento, houve enorme interesse em esquemas de educação não-formal que combinavam trabalho infantil com educação, especialmente na África (Sheffield, Diejomaoh, 1972; Wood, 1974), e programas bilaterais de ajuda ao desenvolvimento promoveram, apoiaram e avaliaram seriamente essas experiências. Por exemplo, o Centre for the Study of Education in Developing Countries (Centro para o Estudo da Educação nos Países em Desenvolvimento), fundado pela agência holandesa de cooperação para o desenvolvimento, criou uma rede internacional para combinar educação e produção, que também recebeu fundos da Agência Suíça para o Desenvolvimento Internacional (SIDA, na sigla em inglês). Essa rede - denominada Education and Production in Theory and Action (Educação e Produção na Teoria e na Ação) - fez um relato dos esforços-piloto na Etiópia, Tanzânia, Zâmbia, Quênia e outros lugares e elaborou uma bibliografia sobre educação-com-produção com cerca de 350 itens (King, 1991). A OIT, em 1988, fazendo uma análise de métodos de proteção à criança trabalhadora, mencionou programas de educação nãoformal e profissionalizante em que as crianças recebiam remuneração enquanto aprendiam. Foi também na década de 1980 que surgiu, na África, uma publicação distribuída internacionalmente, intitulada Education with production (Educação com produção), com artigos de todo o mundo.

\section{A década de 1990}

Esse interesse muito difundido na fusão do trabalho com a educação diminuiu nos anos de 1990. Por quê? Se era uma idéia interessante, com forte apoio ministerial em 1985, por que o apoio a esses programas decresceu dez anos depois? Três fatores parecem ter sido importantes. Primeiro, parte do interesse internacional em se combinar trabalho e educação era originário de países socialistas ou de uma perspectiva socialista. A idéia de trabalho educativo parece ter caído em 
relativo esquecimento com a desintegração do socialismo internacional ao final da década de 1980. A predominância do capitalismo globalizado trouxe mudanças ideológicas tanto de conteúdo como de estilo, e parte dessa mudança parece ter sido a diminuição na ênfase da importância do trabalho como elemento de formação moral e humanizador no desenvolvimento individual e social. Hoje em dia, as idéias otimistas sobre os benefícios do trabalho na formação dos indivíduos, respaldadas pelos ministros de 20 anos atrás, a muitos parecem estranhas e até mesmo inaceitáveis. Estão sujeitas a ser condenadas como brechas perigosas para o trabalho infantil, o que em geral, à época, não se considerava. Alguns desses enérgicos ataques à união de trabalho infantil com educação provêm atualmente do movimento sindical internacional, que se opôs particularmente à insistência das próprias associações de crianças trabalhadoras da África, Ásia e América Latina para que fosse permitido legalmente, às crianças que assim o desejassem, trabalhar e estudar, antes mesmo de terem atingido a idade mínima para isso. Essas crianças organizadas e os adultos responsáveis por elas, baseiam suas reivindicações não só na necessidade econômica de trabalharem meio período, mas também na experiência que têm do trabalho como fonte valiosa de aprendizagem que não pode ser reproduzida na escola (Boyden, Ling, Myers, 1998; International Working Group on Child Labour, 1998; Liebel, 2000; Mi1jeteig, 2000; Schibotto, 1990; Swift, 1997, 1999).

O segundo fator que explica o declínio do interesse em conciliar educação com trabalho pode decorrer da conferência em Jomtien de 1990 e da iniciativa internacional "Educação para Todos" que tinha como objetivo garantir educação básica para quase todas as crianças até o ano 2000. Podese argumentar que essa iniciativa mudou drasticamente a orientação da agenda global da educação em direção à meta de garantia de ensino primário e surtiu o efeito não desejado de desviar a atenção prioritária das questões de relevância e qualidade da educação - da qual fazia parte a discussão da ligação entre educação e trabalho. Tem-se procurado atingir essa meta principalmente pela ampliação dos sistemas de ensino escolar formal. Esse tipo de burocracia centralizada dificilmente focaliza as necessidades particulares de determinados grupos de crianças, especialmente aquelas das classes mais pobres da sociedade. Poucos sistemas se modificam para acomodar o trabalho infantil e muitos são abertamente hostis a essa atividade. No entanto, como os países em desenvolvimento não conseguiram nem chegar perto dessa meta de Jomtien de "educação para todos" até o ano 2000, e com o crescente reconhecimento de que sérios problemas de relevância e qualidade limitam a consecução dessa meta e o desempenho escolar (Watkins, 1999), existe hoje em dia crescente interesse em modelos alternativos que possam 
aproximar a educação do dia-a-dia das crianças. Relevância é o fator essencial da "educação básica" - alfabetização acompanhada de habilidades e informações essenciais para a vida - um conceito qualitativo que a conferência de Jomtien também promovia, mas que foi negligenciado na prática. A maior atenção dedicada aos problemas de relevância e qualidade na educação poderá renovar o interesse na questão de como relacionar a educação com os elementos fundamentais da vida das crianças, que freqüentemente incluem o trabalho. Mas, no presente, o movimento nessa direção ainda é incipiente.

Um terceiro fator que explica o declíno do interesse nos anos 90 em fazer com que o trabalho fizesse parte da educação consiste na dificuldade de instituir mudança tão radical na burocracia educacional. Estudos patrocinados por programas bilaterais e multilaterais de ajuda ao desenvolvimento analisaram problemas dessa ordem e levaram os financiadores a reavaliar as perspectivas de sucesso de unir produção econômica com processo educativo (Gustafsson, 1987; King, 1991). Os documentos da Unesco fazem também alusão a esses problemas de implementação e chama a atenção, especificamente, para a resistência dos professores que, além de não gostarem de mudanças nas rotinas estabelecidas, se preocupam com as novas responsabilidades, para as quais não estão preparados adequadamente nem são adequadamente remunerados (Unesco, 1980).

\section{CONCILIAR TRABALHO COM EDUCAÇÃO É UMA BOA IDÉIA ATUALMENTE?}

O fato de o interesse oficial internacional no assunto "educação e produção" ter diminuído, não necessariamente significa que se trata de uma idéia ruim, seja no passado ou atualmente. Porém, para que seja adotada hoje, a proposta teria que preencher no mínimo três critérios práticos. Primeiramente, precisaria ser necessária, em resposta a uma legítima demanda social. As partes interessadas realmente desejam isso? Em segundo lugar, teria que fazer sentido educacional, seja trazendo as crianças para uma escola ou outro local de aprendizado, seja melhorando seu aprendizado durante o tempo em que estiverem lá. Em terceiro lugar, teria que ser operacionalmente viável, capaz de ser implementada. Analisemos rapidamente como a idéia poderia se sair de acordo com esses três critérios. 


\section{Existe uma demanda?}

A questão da demanda é fácil de responder: a demanda é enorme. Números elevados de crianças estão fora da escola ou freqüentamna de forma irregular, quando isso coincide com compromissos inadiáveis de trabalho. Desse modo, em muitos casos, a solução prática é conciliar trabalho com estudo para que a combinação dos dois seja viável (Boyden, Ling, Myers, 1998). A demanda reflete-se nas conclusões de um recente estudo realizado por Rädda Barnen, com grupos de crianças de seis países africanos, asiáticos e latino-americanos. O objetivo da pesquisa era compreender como as crianças vêem seu trabalho no contexto de suas vidas como um todo e, principalmente, em relação à família e educação. Uma das conclusões mais nítidas foi que mais de três quartos das crianças preferiam uma mistura de trabalho e estudo, a estudo ou trabalho em tempo integral (Woodhead, 1998). Vale a pena lembrar que a Grã-Bretanha conseguiu universalizar a educação basicamente por meio de um sistema de "meio-período" em que tanto o trabalho quanto a escola eram programados de modo que as crianças pudessem participar de ambos. As escolas de "tempo integral" de hoje surgiram muito mais tarde, com o aumento da prosperidade (Cunningham, 1991).

Um outro indicador de demanda é a resposta recebida por programas de educação formal e não-formal, que adaptam sua programação e outras condições, de modo a abranger crianças que trabalham meio período ou que realizam trabalhos temporários. A ONG Bangladesh Rural Advancement Committee - BRAC - (Comitê de Avanço Rural em Bangladesh) tentou, de início, oferecer esquemas flexíveis para crianças que trabalham nas áreas rurais; a resposta foi tão satisfatória que, atualmente, a ONG administra o maior programa de educação não-formal do mundo. A Escuela Nueva, da Colômbia, um importante programa de reforma escolar do governo, também oferece esquemas flexíveis em áreas rurais, onde muitas crianças faltavam às aulas para trabalhar. Esse programa também obteve resposta altamente positiva e foi bem-sucedido ao evitar a evasão escolar (Unicef 1997, 1999). Ao mesmo tempo, é preciso lembrar que nem todas as crianças preferem a opção trabalho-escola. Na Índia e Brasil, por exemplo, crianças que trabalham aderiram a campanhas para substituição do trabalho infantil, mesmo em meio período, por escola em período integral. 


\section{A proposta faz sentido do ponto de vista educacional?}

Para abordar o segundo aspecto - a contribuição educacional do elemento trabalho em esquemas trabalho-estudo - é preciso levar em consideração questões tanto de conteúdo quanto de processo. Em termos de conteúdo educacional, a Unesco entende que trazer elementos do trabalho para a educação pode ajudar o jovem a se preparar para tirar proveito das oportunidades reais de emprego e remuneração (Unesco, 1980). Os sistemas educacionais do Norte da Europa, em que aprendizados organizados desempenham um papel fundamental, há muito oferecem um modelo que visa à integração do estudo acadêmico, treinamento profissionalizante e trabalho produtivo. Os benefícios econômicos e de colocação profissional, advindos de se levar o trabalho para a educação e a educação para o local de trabalho, há muito foram compreendidos tanto em países industrializados quanto em países em desenvolvimento, embora se apliquem somente a crianças que já tenham completado a escolaridade primária, a partir de 12 anos de idade e acima. Porém, em algumas partes do mundo, alguns projetos, como aqueles que abrangem crianças que trabalham e crianças de rua, também englobam crianças mais jovens. Para maximizar os aspectos da educação como geradora de eficiência econômica e de renda, a abordagem "produção e educação" parece ser particularmente poderosa. É conveniente lembrar, no entanto, que a muito alardeada contribuição da educação ao desenvolvimento econômico ocorre basicamente onde os resultados da educação coincidem com oportunidades econômicas e demandas do mercado de trabalho; os analistas questionam até que ponto essa contribuição ocorre quando esses fatores não coincidem (Rubinson, Fuller, 1992).

Com relação aos processos educacionais, a pesquisa atual sobre desenvolvimento infantil e aprendizado sugere as diversas vantagens de se situar o aprendizado dentro de um contexto social apropriado (Abbot, Ryan, 2001; Rogoff, 1990; Valsiner, 2000; Wood, 1998). Porém, quais são os contextos mais apropriados? Diversos pesquisadores do desenvolvimento cognitivo encaram com ceticismo as afirmações de que a escola formal constitua um ambiente de aprendizado particularmente adequado às necessidades das crianças. $O$ primeiro aspecto apontado por esses analistas é a alienação desse ambiente do resto da sociedade, "a introdução da educação formal é um ato de distanciamento social deliberado das crianças de seus contextos coletivo-culturais" (Valsiner, 2000, p. 256). Essa educação descontextualiza o conhecimento, o que é um obstáculo ao aprendizado. A dinâmica da sala de aula, centrada no professor e que faz uso de uma limitada gama de estratégias de ensino, também pode dificultar o aprendizado em lugar de facilitá-lo (Gardner, 1991; Wood, 1998). 
No passado, pressupunha-se que a escola tivesse o efeito de melhorar a mente das crianças, oferecendo habilidades gerais de raciocínio que poderiam ajudá-las a solucionar vários problemas rotineiros de forma mais inteligente. As pesquisas não corroboraram essa hipótese; o que a maior parte das crianças aprende na escola é o que é necessário para sair-se bem na escola e prosseguir nos estudos. Existem poucas indicações de que a escola, além de transmitir informações e habilidades essenciais, como ler, escrever e lidar com números, realmente melhore a capacidade geral das crianças de resolver problemas. Cole e Cole resumem a questão:

A pesquisa que compara o desempenho cognitivo de crianças que freqüentam a escola com o daquelas que não a freqüentam revela que a escolaridade formal, na média infância, intensifica o desenvolvimento de determinadas habilidades cognitivas... Os resultados cognitivos positivos, no entanto, acabam por se restringir aos materiais e procedimentos compatíveis com as práticas da sala de aula. Não existem indicações de que a escola aumente o desenvolvimento cognitivo em geral. (1996, p. 559)

A conclusão é que a escola, na forma tradicional de ensino transmitido em sala de aula, não é um instrumento muito eficiente para ensinar às crianças a maior parte das informações e habilidades de que necessitam para ser bem-sucedidas na vida. A escola já tem dificuldades em número suficiente para dar conta da alfabetização e aritmética.

Se a escola tradicional não é um ambiente particularmente eficiente para aprender habilidades não acadêmicas, qual seria o melhor? Existem fortes indicações de que as crianças aprendem mais "naturalmente" quando são solicitadas a solucionar problemas da vida real, sob supervisão, principalmente quando trabalham com outras crianças em um ambiente interativo. Rogoff (1990) afirma que essa solução interativa de problemas é o principal mecanismo de aprendizado humano, denominando-a adequadamente de "aprendizado de raciocínio" que ocorre por meio de um processo de "participação guiada". Essa visão altamente social do desenvolvimento cognitivo é cada vez mais aceita entre os cientistas sociais, e alguns educadores têm tentado analisar suas implicações para a educação das crianças. Um efeito imediato foi chamar a atenção para recursos educacionais provenientes de uma comunidade mais ampla, múltiplos canais de aprendizado e oportunidades de aprender pela experiência, inclusive por meio do trabalho. A ênfase está em contextualizar de maneira mais eficiente o conhecimento, a inteligência e o processo de aprendizado (Abbott, Ryan, 2001; Gardner 1991, 1999; Sternberg 1997).

As implicações revolucionárias do novo modo de pensar o desenvolvimento e a educação do homem podem ser observadas na forma 
pela qual um grupo, baseado em novas evidências científicas, reformulou os princípios do desenvolvimento cognitivo, para enfatizar o engajamento social como o principal mecanismo de aprendizado (21st Century Learning Initiative, 1997).

1. Aprender é um ato fundamentalmente social e inseparável do engajamento no mundo.

2. O conhecimento está integrado na vida das comunidades; o aprendizado é a forma como as pessoas tornam-se parte da comunidade.

3. O aprendizado é um ato de fazer parte; a motivação para aprender repousa na relação íntima entre o desejo de participar e o papel do novo conhecimento em permitir essa participação.

4. O saber depende do engajamento na prática; somente em sala de aula o conhecimento é apresentado de forma abstrata.

5. O engajamento é inseparável da capacitação; o potencial para aprender é maior em situações nas quais os participantes têm papéis significativos a desempenhar na vida real, papéis esses que têm conseqüências não somente para eles, como também para sua comunidade.

6. A dificuldade de aprender é resultado da exclusão da participação; as pessoas a quem foi negado tornar-se parte com direito a contribuir para a criação de significado, não conseguem se engajar de forma suficiente para aprender facilmente.

7. Por natureza, somos aprendizes por toda a vida; na busca de participar, as pessoas aprendem o tempo todo, porém não necessariamente aquilo que é melhor para elas ou para a sociedade.

Esses princípios podem parecer desorientadores e inacreditáveis, até que alguém os associe a estudos já bastante conhecidos realizados por pesquisadores do desenvolvimento cognitivo. Por exemplo, um conhecido estudo brasileiro, que compara a habilidade matemática de crianças que estudam e trabalham, observou que as que trabalhavam na rua costumavam fazer regularmente cálculos mentais mais difíceis do que os problemas que deveriam resolver em sala de aula, com papel e lápis. No entanto, essas mesmas crianças iam mal nas aulas de matemática. A pesquisa revelou que os métodos de cálculos que utilizavam em seu trabalho eram diferentes daqueles ensinados na escola. Ao analisar o sistema próprio das crianças, um matemático profissional descobriu que o sistema não só era mais prático para o comércio, como também de sofisticação matemática superior àquela ensinada em sala de aula. Pode-se concluir que, para essas crianças, o aprendizado da matemática em um 
contexto social, e com objetivos definidos, era mais eficiente do que estudar as operações matemáticas de forma abstrata (Nunes, Schliemann, Carraher,1993).

Ao analisar maneiras de vincular o aprendizado das crianças com atividades produtivas, de que forma os formuladores de políticas e educadores poderiam pensar a contribuição educacional do trabalho? A Unicef coloca isso de uma forma adequada:

Os valores e habilidades que as crianças aprendem no trabalho não podem ser ignorados como forma de educação, embora algumas das lições possam ser negativas ou com um custo alto demais. As crianças desenvolvem inúmeras habilidades úteis a partir de experiências concretas como o trabalho, incluindo-se aí o uso de ferramentas, negociação, organização do tempo, persuasão e sobrevivência. Existem indicações de que o trabalho moderado pode, em si próprio, ser uma experiência educacional positiva, que aumenta a auto-estima e incute responsabilidade - dois ingredientes fundamentais para o desempenho acadêmico e que pode até mesmo resultar em melhor aproveitamento escolar. (Unicef, 1997)

\section{É possível administrar a proposta?}

A viabilidade é o terceiro critério para se julgar o valor potencial das tentativas educacionais de se trazer trabalho produtivo para a esfera educacional. Essas propostas podem ser implementadas pelas instituições existentes, principalmente as responsáveis pela educação infantil? Embora possa ser relativamente fácil preencher os dois primeiros critérios (de demanda e valor educacional), sua implementação enfrenta sérios obstáculos, principalmente quando se pensa em termos de educação de massa nos sistemas públicos de ensino. Todas as evidências apontam para a extrema precariedade dos serviços educacionais para crianças pobres das áreas rurais e das periferias urbanas - exatamente os locais em que a maioria das crianças vive. Este é um aspecto fundamental da grande crise da educação no mundo de hoje e uma das razões que explicam o insucesso do objetivo universal de oferecer "educação para todos" até o ano 2000. Para se ter noção de sua gravidade, basta examinar duas publicações recentes. A primeira, escrita por um dos mais respeitados analistas educacionais da América Latina, afirma que menos de um quarto dos filhos de famílias situadas na metade inferior da distribuição de renda saem da escola primária (que normalmente dura de quatro a seis anos, dependendo do país) funcionalmente alfabetizados, mesmo que concluam o curso (Schiefelbein, 1997). 
A segunda publicação é um relatório da Oxfam, sobre a educação nos países em desenvolvimento. A melhor notícia da publicação é que o quadro de quase 20 anos de declínio na oferta escolar e qualidade do ensino pode começar a se reverter. Porém, mesmo nas melhores condições, ainda levará muitos anos até que os países mais pobres da África e Ásia possam garantir, na prática, uma educação primária de qualidade minimamente decente a todas as suas crianças (Watkins, 1999). É viável que os sistemas educacionais dos países em desenvolvimento, com todas as suas dificuldades, consigam administrar uma educação de qualidade, mais complicada, que requer maiores recursos, organização e inovação? Diante dessas circunstâncias limitantes, é possível fazer alguma coisa para conciliar ensino com trabalho? Vamos examinar essa questão em termos de diferentes níveis de complexidade das políticas e dos programas.

\section{MODOS DE VINCULAR EDUCAÇÃO E TRABALHO PRODUTIVO}

Que tipos de combinação trabalho-estudo merecem ser seriamente analisados pelos formuladores de políticas e educadores que têm de trabalhar em condições tão limitantes? Existem diversas opções que analisaremos em ordem ascendente de complexidade. A primeira, mais comum e mais fácil de implementar, simplesmente elimina os obstáculos que impedem crianças que trabalham de receber educação, de forma que tanto o trabalho quanto o estudo possam ser acomodados em suas vidas. Esta abordagem se afasta de uma filosofia educacional exclusivista de "aprendizado sem trabalho" - a escola convencional, alienada do restante da vida das crianças, principalmente seu trabalho - para uma mais inclusiva que possa englobar "aprendizado com trabalho". Normalmente, esta abordagem adapta os programas e os processos escolares de forma a tornar possível que as crianças que trabalham possam receber educação. Um segundo modo, "aprendizado a partir do trabalho" ajuda as crianças a refletirem sobre sua experiência de trabalho e com ela aprenderem, tornando-as capazes de se autodefenderem. No próximo nível de complexidade, encontra-se "aprendizado para o trabalho", a conhecida abordagem de ensino profissionalizante em que as crianças aprendem habilidades de trabalho antes de assumir um emprego e, a última, e mais exigente modalidade, é "aprendizado por meio do trabalho", na qual o trabalho é quase que completamente integrado como um mecanismo educacional em si mesmo. Examinemos rapidamente cada uma das alternativas, observando o que elas buscam atingir, como operam e o que é necessário para implementá-las. 


\section{Aprendizado com trabalho}

Esta abordagem é tão comum que requer pouca explicação. Os calendários escolares europeu e norte-americano, que estabelecem férias de verão para os alunos, constituem um exemplo. Remontam a um passado agrícola, quando as crianças precisavam ajudar durante as estações de cultivo e colheita, mas estavam disponíveis para freqüentar a escola durante os meses de inverno. Adaptar o calendário escolar às exigências sazonais em que o trabalho infantil se fazia necessário minimizava o conflito entre o lar e a escola e aumentava as oportunidades de as crianças receberem educação. O programa Escuela Nueva da Colômbia é um exemplo de aplicação dessa abordagem em um país em desenvolvimento. Ali, as comunidades rurais foram capazes de estabelecer um calendário escolar adequado para manter as crianças na escola. Os membros da comunidade, inclusive as crianças, têm o direito de participar nas deliberações sobre o calendário escolar. Originalmente, esse programa era voltado para crianças das áreas produtoras de café, que consistiam em pequenas propriedades agrícolas, administradas por famílias, onde as estações de pico de demanda do trabalho infantil não coincidiam com as férias escolares do país. Atualmente, aplica-se à maior parte das áreas rurais (Unicef, 1999). Na Ásia, o Bangladesh Rural Advancement Committee BRAC - opera um extenso programa de educação não-formal, que teve início em resposta às necessidades específicas de crianças das áreas rurais que precisam trabalhar ao menos uma parte do dia. Com calendários flexíveis e outras inovações, o programa contribuiu para ampliar significativamente a participação no ensino rural e elevar as taxas de alfabetização, principalmente de meninas (Ahmed et al., 1993). Uma abordagem mais pró-ativa é levar a educação até as crianças em seu local de trabalho, de acordo com suas necessidades e horários, em vez de pedir que freqüentem a escola em um local determinado. Essa abordagem envolve também modificações no programa e organização do trabalho das crianças. Quase sempre, as crianças, as famílias e os empregadores estão dispostos a fazer tais mudanças, desde que os sistemas educacionais também se adaptem (Haspels et al., 1999). Em todo o mundo, os programas educacionais para crianças que trabalham na rua oferecem "escolas de calçadas" ou outras atividades educacionais que vão até a criança, geralmente como uma primeira etapa para trazer as crianças para o sistema regular de ensino. A abordagem "aprendizado com trabalho" enfatiza a coexistência de trabalho e estudo, porém não busca transformar o trabalho em ferramenta de aprendizado ou melhorar a situação das crianças. Coordenando escola e as responsabilidades de trabalho das crianças, esse 
modelo pode levar a educação a um grande número de crianças que trabalham e que, sem essa alternativa, não conseguiriam estudar.

\section{Aprendizado a partir do trabalho}

Esta abordagem pode oferecer uma das mais poderosas formas de educação. Diversos projetos de educação não-formal e alguns programas escolares levam crianças que trabalham a refletir sobre sua experiência de trabalho e dela extrair lições, bem como a utilizar sua percepção para poder proteger a si próprias e aos seus interesses. Existem indícios de que a reflexão é essencial para efetivamente aprender a partir da experiência do trabalho (Perreault, 2000; Swift, 1997). Nesta abordagem, a ênfase educacional está na conscientização e não na transmissão de novas informações. O objetivo é reforçar a capacidade das crianças para lidar com situações relacionadas ao trabalho, muitas das quais são perigosas ou particularmente difíceis. Em muitos casos, esse tipo de educação faz parte de uma abordagem mais mobilizadora que leva as crianças a se unirem em ação coletiva para sua proteção mútua. Em diversos países, tornou-se a estratégia predominante para abranger crianças que trabalham na rua e outros jovens que preenchem o perfil, geralmente por meio de "educadores de rua" que, em programas mais bem desenvolvidos, são rigorosamente selecionados e treinados. Crianças que trabalham em tarefas realizadas nas ruas geralmente são agrupadas de acordo com sua ocupação e área, formando grupos informais de discussão e ação que têm determinados problemas e experiências em comum. Por exemplo, crianças que trabalham como carregadores em um mesmo mercado, têm problemas em comum de abuso policial, tentativas de trapaças por parte dos fregueses e donos de bancas, falta de instalações sanitárias e assim por diante. O educador de rua e outros membros do programa ajudam as crianças a aprender como analisar seus problemas de forma disciplinada, apresentar soluções, chegar a um consenso e adotar um plano de ação - geralmente com a ajuda de adultos que participam do programa sempre que necessário, sem retirar a iniciativa das próprias crianças. Os adultos que monitoram esses processos quase sempre observam os nítidos benefícios em termos de aprendizado, auto-estima e socialização adquiridos pelas crianças (Schibotto, 1990; Myers, 1988; Tolfree, 1998; Swift, 1997).

Aprender a partir do trabalho pode ser apropriado principalmente para crianças que estejam na média infância e início da adolescência, precisamente à época em que o abuso do trabalho infantil constitui a maior ameaça. Tem-se observado que, nessa faixa etária, a discussão em grupo face a face é um modo bastante eficiente de "instrução para a 
compreensão" que é a conscientização dos princípios e o desenvolvimento da verdadeira percepção. Esse trabalho em grupo facilita também a aquisição da capacidade de ler e escrever (Gardner, 1991). Aprender em grupo pode ter efeitos marcantes sobre o desenvolvimento. Entrevistas realizadas com ex-trabalhadores de rua no Brasil e Peru indicam que muitas pessoas que passaram por esse tipo de experiência educacional reconhecem que isso transformou suas vidas, tornando-as mais conscientizadas do ponto de vista social e político, motivadas a serem mais solidárias e trabalhando em prol de justiça social e econômica. Elas vinculam o desenvolvimento cognitivo com objetivos de crescimento espiritual e progresso social (Swift, 1997, 1999).

Em alguns casos, uma das funções do educador de rua é atrair as crianças para programas educacionais estruturados, deslocando a "escola da vida" rumo à alfabetização, assim como à solução de problemas de trabalho. Um exemplo disso é o AXÉ, um amplo programa que é realizado em Salvador, Brasil. Os educadores de rua começam reunindo crianças em pequenos grupos, em seu ambiente de trabalho, para discutir problemas imediatos. Com o passar do tempo, ampliam o horizonte estimulando-as a pensarem sobre suas vidas a um prazo mais longo e a completarem, no mínimo, a educação básica. Quando as crianças tomam essa decisão, o local de ensino passa da rua para um programa educacional não-formal, altamente flexível, que as ajuda a adquirirem habilidades básicas de leitura, escrita e aritmética, ao mesmo tempo envolvendo-as em atividades culturais recreativas que reforçam sua auto-estima e a integração à comunidade. Em seis ou mais meses, a maioria das crianças em idade escolar atinge um nível de alfabetização e habilidade com números que as habilita a ingressarem no sistema educacional formal de sua faixa etária. Quando estão preparadas para serem bem-sucedidas na escola, as crianças são inseridas no sistema educacional regular. Durante todo o processo, porém, as crianças mantêm o poder de decisão sobre suas próprias vidas, com os adultos desempenhando o papel de mediadores e conselheiros. Fica a critério delas continuar ou não a trabalhar (Haspels et.al., 1999; Reis, 1993).

Embora essa abordagem de grupo de aprendizado a partir do trabalho tenha sido desenvolvida basicamente por programas de educação não-formal, ela tem potencial considerável para tornar o ensino formal importante para as crianças que trabalham. A reflexão, em sala de aula, sobre o trabalho das crianças, seja ele realizado em casa ou fora dela, pode transformá-la em uma verdadeira experiência de aprendizado. Uma nítida vantagem dessa abordagem de integrar trabalho e estudo é que ela se adapta às estruturas educacionais formais ou não, sem incorrer em custos adicionais. Não há razão material por que escolas individuais, ou mesmo 
sistemas educacionais como um todo, não possam incorporá-las com relativa facilidade. No entanto, existem poderosos obstáculos de natureza não material, pois os processos democráticos participativos envolvidos se chocam diretamente com o sistema cultural autoritário e a competência limitada do professor da maioria dos sistemas formais de ensino. Este é principalmente o caso das escolas de baixa qualidade dos países pobres que, na maioria das vezes, são as únicas disponíveis para as crianças que trabalham. Por ora, esta abordagem provavelmente se aplique mais aos programas de educação não-formal que são mais centrados na criança, mais capazes e mais alinhados com a inovação.

\section{Aprendizado para o trabalho}

Esta forma popular de combinar trabalho e estudo enfatiza a responsabilidade dos educadores quanto ao preparo das crianças para o trabalho, no mínimo como futuros adultos. Seu exemplo mais comum é o ensino profissionalizante, na forma de aulas dedicadas a ensinar um ofício às crianças. Geralmente estruturado como atividade de período integral que acompanha no mínimo a escolaridade primária ou outro ensino básico, está aberto somente àquelas crianças que já estejam minimamente alfabetizadas e com habilidades para lidar com números. A abordagem geralmente pressupõe um estágio em que o trabalho se resume a acompanhar a sua preparação. Em alguns casos, porém, oferece treinamento profissional paralelamente à escolaridade formal ou ensino não-formal de alfabetização e habilidades para a aritmética, talvez como incentivo para manter as crianças envolvidas até que estejam alfabetizadas.

O ensino voltado para a ocupação profissional quase sempre goza de popularidade, uma vez que atende à expectativa de que a educação deve garantir um benefício econômico. Em todo o mundo, em países ricos e pobres, os programas de treinamento formais ou não formais, ensinam às crianças habilidades ocupacionais que as ajudem a ter um meio de vida decente. Onde esse tipo de treinamento é bem sucedido, tende a ser popular entre pais e crianças pobres. Em alguns casos, porém, pais, crianças e até mesmo educadores têm se mostrado resistentes ao ensino profissionalizante como uma forma inferior de educação que limita o pobre a técnicas manuais que conferem baixo status e reduzem seu acesso às profissões de "colarinho branco", de status social elevado. Essa reação tem sido mais observada em países que, no período pós-colonial imediato, não tinham cidadãos suficientemente instruídos para substituir os funcionários públicos, escriturários, contadores e outros que trabalhavam nas burocracias do setor público e do setor privado e que haviam sido 
expatriados. À medida que os países recém-libertados lutavam para suprir esse déficit, a simples conclusão da escola secundária foi, durante alguns anos, suficiente para garantir um emprego de "colarinho branco" estável, razoavelmente bem remunerado e que também conferia status social elevado. Nesse tipo de mercado de trabalho, a escolaridade-padrão era vista, na verdade, como uma forma altamente prática de preparação vocacional. As expectativas públicas dos pobres estavam condicionadas por essa equivalência de escolaridade com emprego não manual e de status elevado. Essas expectativas perduraram em muitos locais, apesar da saturação do mercado de trabalho para pessoas instruídas e as altas taxas de desemprego e subemprego entre aqueles que concluíam a escolaridade. A participação educacional diz respeito aos benefícios econômicos externos, e não aos valores intrínsecos de aprender; os pobres querem ter um treinamento profissionalizante que os capacite a conseguir um emprego decente, preferivelmente no serviço público (Foster, 1965; Fuller 1991).

Existem muitos exemplos bem-sucedidos do modelo educacional profissionalizante, patrocinados por ONGs ou empresas. Um deles é o Underprivileged Children's Education Programme - UCEP - (Programa de Educação para Crianças Desprivilegiadas) de Dacca, Bangladesh, que tem uma longa lista de alunos treinados, provenientes de cortiços urbanos ${ }^{1}$, e que conseguiram um emprego. Trata-se de um programa de educação básica cujo enfoque está na aquisição de leitura, escrita e aritmética, necessárias para se aprender um ofício. Quando atingem essa qualificação, as crianças passam por um treinamento em diversos ofícios. A UCEP mantém relacionamentos com as indústrias locais para garantir que os alunos formados tenham oportunidades efetivas de emprego e que sejam adequadamente preparados para tirar proveito das oportunidades. O programa oferece não somente ensino e treinamento, como também ajuda a encontrar e manter um emprego. Ao final do período de treinamento, ou antes, a grande maioria dos alunos consegue encontrar um emprego adequado. O segredo do sucesso da UCEP está na sua ligação com empregadores, fontes de recursos financeiros, pais e as comunidades pobres de onde provêm os alunos, e na forma como administram essas relações.

Os custos constituem o principal problema do modelo educacional profissionalizante. Embora a UCEP tenha conseguido manter um alto nível de qualidade do programa, sua sobrevivência depende de recursos externos. Os custos são muito superiores àquilo que o governo federal

\footnotetext{
${ }^{1}$ As informações aqui apresentadas sobre a UCEP foram coletadas pelo autor em visitas de campo e foram checadas pelo escritório da Save the Children Sweden (Salvem as Crianças Suécia), em Dacca, que recentemente avaliou o programa.
} 
normalmente paga pela escolaridade e além daquilo que considera ser justificável investir em uns poucos favorecidos. O elevado conceito de que goza, tem garantido à UCEP considerável apoio externo. Porém, essa dependência da ajuda externa faz com que seu futuro, mesmo a curto prazo, seja sempre incerto. Esta situação parece típica dos programas de preparação profissional oferecidos aos pobres. Para alcançar sucesso mais amplo, o modelo dependeria de encontrar maneiras viáveis de conseguir preencher suas necessidades financeiras. Sugeriu-se que os usuários pagassem pelo curso por meio de empréstimos educacionais, a serem saldados depois que o aluno começasse a trabalhar (Grootaert, Patrinos, 1999); porém, esses empréstimos são raros e difíceis de serem obtidos nos países pobres. Na melhor das hipóteses, o máximo que se consegue é financiamento de parte dos custos.

Uma alternativa para reduzir os custos é utilizar as instalações, pessoal e equipamento do empregador, em vez de o próprio programa oferecer espaço, instrutores e maquinário. Em diversos países industrializados, esse esquema tornou-se uma estratégia importante de treinamento. Em alguns países em desenvolvimento, o arranjo foi utilizado também para o treinamento técnico topo de linha de jovens e adultos e é indicação de qualidade de programas de experiência de trabalho comuns em escolas secundárias nos países ricos. Nos países em desenvolvimento, seu potencial para adolescentes em idade escolar poderia ser explorado muito mais agressivamente, principalmente quando combinado com programas de alfabetização ou outros programas de educação básica. Isto já está ocorrendo em alguns lugares. Por exemplo, em Dacca, Bangladesh, a Unicef e outras organizações têm feito experiências como forma de oferecer oportunidades de treinamento no trabalho para crianças provenientes de cortiços urbanos, que tenham sido alfabetizadas por meio de programas especiais de educação básica. Em um desses projetos, meninas que atingiram um nível básico de alfabetização e que estejam em idade legal para trabalhar, são treinadas a usar os mais modernos equipamentos industriais de costura para poder se qualificar para cargos mais elevados em indústrias de vestuário sofisticado. Uma empresa do setor fornece o espaço, o equipamento e o treinamento técnico, enquanto a Unicef e outras organizações fornecem outro tipo de apoio para as meninas. Aquelas que concluem o período de treinamento podem assumir cargos em uma confecção de roupas ou, caso consigam ter acesso a uma máquina de costura, trabalhar como autônomas. ${ }^{2}$

Um outro problema enfrentado pelo modelo de treinamento profissionalizante é o risco de saturação dos mercados de trabalho do

${ }^{2}$ Comunicação pessoal da Unicef em Dacca. 
"setor moderno" com habilidades em que o treinamento é oferecido. Nas regiões e países mais pobres, a demanda do setor formal por trabalhadores com uma habilidade específica pode ser bastante limitada. Algumas organizações lidam com esse problema treinando crianças e jovens para serem autônomos. Por exemplo, a República do Pequeno Vendedor, um programa voltado para crianças que trabalham e crianças de rua de Belém, Brasil, durante longo tempo patrocinou o treinamento em consertos de pequenos dispositivos e habilidades similares, que capacitariam os alunos a estabelecer seus próprios negócios no setor informal da economia nas comunidades onde viviam; porém, a demanda é pequena até mesmo para esse tipo de serviço. ${ }^{3}$ A ONG canadense Street Kids International (Programa Internacional de Ajuda a Crianças de Rua), que apóia o trabalho com crianças de rua de vários países, está atualmente produzindo e testando um audiovisual de treinamento que pode ser utilizado pelos educadores de rua para ajudar as crianças a desenvolverem suas próprias atividades que gerem renda. ${ }^{4} \mathrm{O}$ treinamento para o trabalho autônomo de crianças não se limita aos países pobres. Nos Estados Unidos, por exemplo, é possível encontrar em livrarias (virtuais ou não) material atrativo para instruir crianças e adolescentes sobre como estabelecer seus próprios negócios de meio período. Diversas escolas de ensino fundamental e médio têm até aulas após o horário escolar e clubes que auxiliam os alunos interessados em desenvolver tais projetos.

Um aspecto totalmente diferente de "aprendizado para o trabalho" diz respeito a alertar as crianças para os perigos e problemas do local de trabalho e muni-las de informações e habilidades para serem agentes mais efetivos de sua própria proteção. Esse tipo de treinamento foi bastante comum em programas de educação não-formal para crianças de rua, crianças prostitutas e outras crianças que exerciam formas particularmente perigosas de trabalho. Esse tipo de treinamento fazia parte de um programa patrocinado pela OIT para lixeiros de Manila, Filipinas, por exemplo (Gunn, Ostos, 1992). A Casa de Passagem, um programa dirigido a jovens prostitutas, em Recife, Brasil, tem como prioridade ensinar jovens, que estejam em risco extremo, como proteger-se contra doenças, principalmente AIDS e contra o tratamento abusivo por parte de clientes e autoridades policiais (Bequele, Myers, 1995).

Muito pode ser feito para transmitir informações desse tipo nas escolas. Por exemplo, Child Workers in Asia - CWA - (Trabalhadores Infantis da Ásia) preparou material audiovisual e impresso a ser usado nas escolas asiáticas e programas educacionais não-formais, com o objetivo de

\footnotetext{
${ }^{3}$ Visita de campo e comunicação pessoal com Pde. Bruno Sechi.

${ }^{4}$ Comunicação pessoal da SKI. 
advertir as crianças da área rural sobre os perigos de migrar para cidades à procura de trabalho e instruí-las sobre como procurar ajuda se tiverem problemas. ${ }^{5}$ GSS, um programa educacional não-formal de Bangladesh, incorporou ao seu programa básico de alfabetização informações sobre os abusos do trabalho infantil, as leis trabalhistas locais e nacionais, os direitos dos trabalhadores, a organização dos sindicatos e outros tópicos pertinentes (visitas de campo ao GSS). Nos Estados Unidos e Europa, adolescentes de muitas escolas secundárias estaduais recebem rotineiramente informações similares em suas escolas e alguns deles são de opinião de que isso já deveria ter sido feito antes. A idéia de todos esses programas é capacitar as crianças que trabalham a se tornarem mais ativas e a defenderem seus próprios direitos, saúde e segurança. É possível alcançar um nível mais elevado de educação de caráter protetor por meio dos programas educacionais formais e não-formais, a um custo mínimo. Até mesmo os países pobres e os programas que não são capazes de administrar adequadamente ou financiar programas de treinamento profissional podem ensinar às crianças medidas de precaução a serem observadas em seu local de trabalho, seus direitos legais e como usar os recursos sociais para sua proteção.

\section{Aprendizado por meio do trabalho}

Embora Rogoff sugira que todo o ato de aprender das crianças seja um "aprendizado de raciocínio", vamos considerar aqui as relações estruturadas do tipo "participação guiada" entre jovens discípulos e trabalhadores mais habilitados que, durante muitos séculos e culturas, forneceram os meios para transmitir habilidades de uma geração a outra. Em qualquer tipo de esquema de aprendizado prático, as crianças ou jovens desempenham as atividades sob a orientação de uma pessoa mais capacitada, em geral, mas não necessariamente, um adulto, com ou sem remuneração, como forma de treinamento. $\mathrm{O}$ próprio trabalho pode ser estruturado de forma a oferecer aprendizado prático, assim como produção. Existem muitas modalidades de aprendizado, formais e informais, individualizadas e coletivas. A mais comum refere-se ao trabalho não-remunerado que as crianças realizam em casa, sob a supervisão de membros da família; porém, muitas sociedades dispõem também de mecanismos para colocar crianças com outros adultos considerados capazes e dispostos a ensinar habilidades valiosas como forma de pagamento pelo trabalho realizado. Alguns especialistas afirmam

${ }^{5}$ Comunicação pessoal e newsletters da CWA. 
que o aprendizado prático é, de longe, o mais importante e viável meio de integrar aprendizado e trabalho, inclusive em sociedades tecnologicamente sofisticadas. De acordo com as palavras de Gardner

Os aprendizados práticos podem ser considerados os meios de instrução que contribuem mais efetivamente para as formas pelas quais a maioria dos jovens aprende. Esses meios de instrução são favoravelmente entremeadas por experiência sensório-motoras e pelo uso contextualizado de simbolizações de primeira ordem, tais como a língua nativa, desenhos e gestos simples. No que diz respeito a notações ou conceitos mais formais, eles são apresentados ao aluno diretamente no contexto em que são necessários e ele decide por si próprio os modos pelos quais podem ser aplicados. Neste ponto, as diferenças em relação à escola formal ficam mais evidentes... Eu afirmo que a maior contribuição de um sistema de ensino para a aquisição do conhecimento encontra-se na combinação de certas características de aprendizados práticos com certos aspectos de escolas e outras instituições, tais como museus para crianças. Essa combinação pode vincular formas inusitadas de aquisição de conhecimento que, quando separadas, quase sempre anulam os esforços no sentido de alcançar a verdadeira compreensão. (1991, p.25)

Se os aprendizados práticos são tão promissores, por que não fazem parte do ensino formal, patrocinado pelo Estado, principalmente para crianças de famílias pobres das regiões em desenvolvimento? Uma resposta é que os aprendizados chamados "tradicionais", não regulamentados, faziam parte dos costumes sociais na Europa préindustrial e em muitos países em desenvolvimento, hoje em dia, são feitos de modo explorador, ou encarados como tal, e, por isso, vistos com desconfiança pelo governo, sindicatos, organizações de defesa dos direitos das crianças e muitos educadores. Porém, seu potencial para alcançar um elevado número de crianças é tão grande que alguns programas, tais como o International Program to Eliminate Child Labour - IPEC - (Programa Internacional para Erradicação do Trabalho Infantil) da OIT, estão tentando melhorar suas condições de trabalho e a qualidade do prepraro que oferecem. ${ }^{6}$ Outros sugerem que a abordagem do aprendizado prático simplesmente "saiu de moda" e que a preferência atual por uma escolaridade "moderna", descontextualizada e desvinculada do trabalho, é melhor explicada como uma questão de moda do que em termos de benefícios educacionais, econômicos ou sociais comprovados (Ramirez, Ventresca, 1992; Rubinson, Fuller, 1992; Gardner, 1991).

Embora tenha sido de certa forma negligenciada pelas políticas educacionais atuais, a abordagem de "aprender por meio do trabalho" não

\footnotetext{
${ }^{6}$ Apresentação durante um workshop sobre trabalho infantil, no Save the Children Alliance (Aliança Salvem as Crianças), de Burkina Faso, em outubro de 1999.
} 
foi esquecida. Tanto os países industrializados quanto os em desenvolvimento criaram programas educacionais experimentais e alternativos, na tentativa não só de vincular educação institucionalizada e trabalho, como também basear a educação, ao menos em parte, na participação em atividades produtivas. Não existe falta de interesse pela idéia de que as crianças poderiam aprender melhor a ler, escrever, fazer cálculos, cooperar, liderar e ganhar a vida se o ensino fosse vinculado à solução de problemas econômicos e técnicos reais, relacionados ao trabalho que realizam. A África tem uma longa história de ensino estruturado dessa forma, em parte devido ao fato de que isso se relaciona ao modo como as crianças viviam e aprendiam em ambientes tradicionais e em parte porque muitas escolas missionárias adotaram uma filosofia de educação por meio de trabalho (Sheffield, Diejomaoh, 1972).

Diversos países fizeram experiências concretas, tentando contextualizar a educação por meio do trabalho, em alguns casos até mesmo formalizando-a como parte da política educacional do governo. Um dos primeiros casos, bastante conhecido, refere-se à Índia pós-colonial, em que a tecelagem manual e outros ofícios exercidos no ambiente familiar foram incorporados ao currículo-padrão escolar para todos os estudantes, como deferência à visão idealista de Gandhi de criar, nas aldeias, economias baseadas em ofícios como principal meio de vida das populações rurais. Na África, a Botsuana, a Tanzânia e o Zimbabue constituem exemplos particularmente dignos de nota. Talvez o caso mais conhecido seja o modelo "Swaneng Hill", originado pela vinculação de uma inovadora escola particular na Botsuana rural com a organização dos estudantes em "brigadas" de trabalho produtivo, que geravam tanto conhecimento quanto renda. Cada brigada assumia um tipo particular de atividade geradora de renda: agricultura, criação de animais, construção, etc. A educação era vista como uma forma de preparar os jovens para lidar com todos os aspectos desse tipo de empreendimento. $\mathrm{O}$ objetivo era criar um sistema de ensino apropriado para o contexto, capacitando os jovens da área rural a progredirem em sua própria região e cultura, desestimulando o êxodo para as cidades e estilos de vida ocidentais, que pareciam ser o resultado inevitável da educação formal. Pretendia ser também uma forma africana de educação, para o desenvolvimento da África, desenvolvendo a pessoa como um todo, vinculando teoria e prática, dentro da estrutura conceitual daquilo que era, à época, conhecido como "socialismo africano" (Gustafsson, 1987).

A Swaneng Hill Secondary School (Escola Secundária Swaneng Hill) e suas brigadas eram conhecidas internacionalmente, em parte devido aos substanciais recursos externos recebidos (principalmente da Suécia) e por que seu fundador, um refugiado político sul-africano, escrevia muito sobre 
suas idéias e sobre o progresso da instituição. Apesar de alguma relutância por parte dos estudantes em aprender habilidades rurais em vez de serem preparados para o serviço civil nas cidades, aparentemente o modelo conseguiu atingir muitos de seus objetivos de aprendizado, tornando-se um agente tanto do desenvolvimento individual quanto comunitário.

Apesar disso, o programa não conseguiu sobreviver à política dos grupos de interesse. Foi incapaz de nadar contra a corrente das escolas ocidentais e da cultura e expectativas políticas criadas em torno delas. Mais que isso, tornou-se evidente que os alunos que trabalhavam para custear a maioria dos custos de sua educação, não conseguiam produzir de forma eficiente ao mesmo tempo em que estudavam. Conseqüentemente, o programa teve de ser subsidiado como um programa educacional do governo e, apesar da resistência, gradualmente foi cedendo às políticas, objetivos, normas e métodos estabelecidos pelo Ministério da Educação com vistas a um sistema baseado nos modelos formais de escolas ocidentais (Gustafsson, 1987). Este caso, e outros similares, indicam que mesmo um modelo de educação baseado em trabalho que seja viável em nível escolar individual não consegue sobreviver, a menos que sejam feitas mudanças fundamentais no modo de pensar e operar dos sistemas de educação nacionais para acomodar o modelo. Esta é a mesma conclusão de experiências trabalho-estudo menos revolucionárias, em sistemas educacionais de países ricos, nos quais os alunos passam parte do tempo na sala de aula e parte realizando algum tipo de trabalho em que aprendem habilidades ao realizar tarefas.

Há muito tempo tem-se afirmado que as pessoas aprendem melhor quando aprendem habilidades no contexto em que as informações são usadas. A educação baseada em trabalho, uma variante especial desse conceito, pode oferecer um enfoque para o aprendizado acadêmico e influenciar significativamente o desenvolvimento intelectual dos jovens... Mas os programas educacionais baseados em trabalho só podem gerar esses benefícios em conjunto com reformas significativas na estrutura das escolas e da escolaridade. Se os programas forem simplesmente transplantados para estruturas tradicionais, serão de pouca valia. De fato, nesse caso, os programas poderiam ser considerados não somente de uso marginal, como também concorrentes do aprendizado acadêmico. Se as escolas desejam ter a oportunidade de desenvolver as possibilidades de emprego e as interações correspondentes com os empregadores, que um sistema efetivo escola para o trabalho exige, elas terão de fazer mudanças significativas na programação e em outras atividades. (Poczik, 1995, p. 56)

Nos países industrializados, o escopo dos programas "aprendizado por meio do trabalho" muitas vezes abrange atividades de trabalho voluntário, quase sempre na forma de programas de "serviço 
comunitário" patrocinados pela escola. Em geral, os participantes concordam em apresentar-se como voluntários para obrigações regularmente programadas, tais como atuar como tutor de crianças menores com necessidades especiais. Ao ampliar a definição do trabalho para incluir o serviço voluntário, abre-se um mercado que, de outra forma, não conseguiria acomodar todos. Em alguns países industrializados, esse tipo de serviço é requisito para a conclusão da escola média ou secundária, e Krishna (1996) informa que ele existe também na Índia. Estudos de acompanhamento, inclusive grupos de discussão com as crianças envolvidas, sugerem que as atividades são úteis para ensinar responsabilidade às crianças e para aprofundar sua auto-estima, iniciativa e identidade cívica (Yates, Youniss, 1999; Youniss, Yates, 1997; Perreault 2000).

É preciso notar que, além do que pode ser obtido com e por meio das escolas e do setor privado, as oportunidades de "aprendizado por meio do trabalho" podem ser abundantes por outros canais. Alguns países industrializados dispõem de inúmeras possibilidades. Nos Estados Unidos, por exemplo, diversas comunidades rurais têm um ou mais clubes $4-\mathrm{H}$, originalmente estabelecidos sob o patrocínio de serviços extensivos de agricultura, para ensinar às crianças e jovens das áreas rurais importantes habilidades agrícolas e de negócios. Eles fazem parte de uma estratégia de extensão de serviços para criar uma clientela aberta às mudanças tecnológicas na agricultura. As crianças ou jovens que participam desse programa normalmente têm um ou mais projetos - por exemplo, a criação de animais - pelos quais são totalmente responsáveis e para os quais são treinados nas habilidades necessárias. Os membros do clube são orientados por líderes voluntários - geralmente agricultores da região e suas esposas e crianças mais velhas que ajudam as mais novas. Atualmente, os clubes 4$\mathrm{H}$ não são exclusivamente rurais e dirigem vários tipos de atividades educativas para os jovens do centro decadente, entre outros. Diversas áreas urbanas são servidas também pelo Junior Achievement, um programa nacional de desenvolvimento empresarial para crianças e jovens. Sob a tutela de homens de negócios da região, que atuam como voluntários, as crianças inventam, fundam e operam pequenas empresas. Tanto o $4-\mathrm{H}$ quanto o Junior Achievement treinam voluntários adultos, fornecendo-lhes material de apoio (impressos e recursos audiovisuais); normalmente, ambos se reúnem nas escolas. Ironicamente, essas oportunidades para que as crianças aprendam com trabalho que gera dinheiro, concentram-se nos países mais ricos, em que a maioria das crianças vê isso como recreação, e são raros nos países pobres, nos quais a renda é muito mais necessária. 


\section{IDÉIAS E OBSERVAÇÕES FINAIS}

As questões e exemplos apresentados acima sugerem uma ampla variedade de complexos relacionamentos entre trabalho infantil e educação, em que as variáveis de trabalho afetam o comportamento educacional e as características educacionais afetam a incidência e o impacto do trabalho infantil. Diferentes tipos de trabalho e condições de trabalho afetam de diversas formas a educação das crianças. Alguns impedem de tal forma a participação na escola ou em outros programas educacionais que deveriam ser desestimulados como inadequados para crianças. Outros têm pequeno efeito, seja positivo ou negativo, sobre as atividades de aprendizado das crianças. Alguns tipos de trabalho estimulam a iniciativa e ensinam habilidades valiosas, enquanto outros impedem o desenvolvimento mental e reduzem o potencial humano. Em alguns casos, esquemas como os aprendizados práticos, que ao mesmo tempo reforçam trabalho e educação, promovendo o desenvolvimento das crianças, devem ser estimulados como benéficos.

Ao mesmo tempo, a educação tem impacto variável sobre o trabalho infantil. Escolas de boa qualidade, acessíveis para o pobre, tendem a reduzir o trabalho infantil, pois até mesmo famílias de baixa renda normalmente se sacrificam para garantir uma educação básica para seus filhos, principalmente se sentirem que a educação produz uma compensação econômica. A educação pode garantir diretamente oportunidades de renda certa para crianças ou prepará-las para serem bem-sucedidas e proteger-se em seu emprego, gerando dessa forma trabalho infantil, porém de um tipo aceitável. Por outro lado, as falhas da educação estimulam as crianças a trabalharem. Muitas crianças conseguem freqüentar a escola, ou mandar seus irmãos, só porque trabalham para poder arcar com as despesas decorrentes - um exemplo de como o trabalho infantil pode elevar as taxas de freqüência escolar. Quando as escolas são particularmente ruins e abusivas, as crianças a abandonam e passam a trabalhar como atividade alternativa, exemplo de como as escolas podem ser causa direta do trabalho infantil.

Diversas pesquisas sobre a relação entre trabalho infantil e freqüência e desempenho escolar cada vez mais sugerem que não compreendemos bem de que forma os dois fatores influenciam um ao outro, ou mesmo o sentido de causalidade quando uma aparente relação é encontrada. Por exemplo, quando os dados indicam uma associação totalmente negativa entre a incidência de trabalho infantil e os níveis de participação ou desempenho escolar, raramente fica claro se essa relação deve-se mais aos efeitos do trabalho sobre a escolaridade ou às falhas da escola sobre o trabalho - ou aos efeitos de um fator comum, tal como 
pobreza ou discriminação. Em resumo, são tantas as variáveis a afetarem as relações entre educação e trabalho infantil que não é possível dizer que exista um único padrão dominante; por isso, não é sensato presumir automaticamente que os dois fatores tendem a entrar em conflito. Isto sugere que as políticas baseadas em tal pressuposição, sem a confirmação empírica da região que está sendo analisada, correm o risco de serem impróprias para as circunstâncias. Educadores e formuladores de políticas fariam melhor se mantivessem uma postura de ceticismo diante de hipóteses estabelecidas a priori sobre as relações entre educação-trabalho infantil e adotassem uma postura voltada para o empiricismo, tanto no que se relaciona à política educacional quanto à política sobre o trabalho do menor.

Para poder lidar com tal complexidade, os formuladores de políticas educacionais e políticas sobre trabalho do menor, que procuram garantir a todas as crianças uma educação decente e proteção contra abusos no local de trabalho, devem ter acesso a uma extensa gama de opções para intervir tanto na educação quanto no trabalho, inclusive às opções que possam ser adaptadas para as circunstâncias das crianças. Esta discussão constitui somente um preâmbulo à riqueza de possibilidades. Comparativamente, as políticas convencionais que estabelecem que as crianças não devem realizar trabalho de qualquer tipo e obrigam-nas a freqüentar a escola, seja de que qualidade for, parecem estranhamente contraídas, mal-adaptadas e injustas. Em muitas situações, os tradicionais mecanismos legais acerca da educação compulsória e proibição de trabalho infantil podem parecer estreitos demais para lidar com a complexidade dos problemas, muito genéricos para adequar-se às especificidades dos contextos, excessivamente governamentais para conseguir mobilizar os principais recursos da sociedade e pouco criativos para tirar vantagem dos poderosos, porém quase sempre sutis, incentivos que mais promovem mudanças. O que é necessário é flexibilidade para abordar de maneira efetiva, no contexto de determinado país, as principais relações entre trabalho infantil e educação, em toda sua variedade e complexidade. Em algumas circunstâncias, o mais correto seria tratar os dois aspectos como concorrentes mutuamente exclusivos do tempo e atenção das crianças; porém em muitos (provavelmente na maioria) dos casos, seria mais útil adaptar trabalho e educação um ao outro, de forma a permitir que cada um tenha espaço suficiente na vida e desenvolvimento das crianças. Antes de se comprometer com outras hipóteses e prescrições tradicionais que presumem uma nítida linha de demarcação entre educação e trabalho, os educadores e formuladores de políticas poderiam concluir que vale a pena considerar toda a gama de abordagens possíveis descritas acima, para conciliar os dois. 
A discussão acima sugere também que restrições de natureza prática impõem um limite o quanto as políticas e programas podem ir para acomodar trabalho e educação. Incorporar considerações sobre trabalho infantil no currículo complica o ensino e a administração escolar. É aconselhável considerar os problemas com que alguns ministros da educação se deparam ao tentar implementar, de maneira bem-sucedida, os mais simples modelos de educação primária. Não parece sensato acrescentar outros fatores à mistura em sistemas já tensionados ao ponto máximo. Contudo, conforme foi indicado, a experiência de países em desenvolvimento, tão diferentes entre si quanto Colômbia e Bangladesh, sugere que muita coisa pode ser feita com os sistemas já vigentes e verbas que sejam realistas para os países envolvidos. Por exemplo, tornar mais flexíveis os calendários e programações de escolas rurais para acomodar a sazonalidade agrícola não parece desorganizar seriamente nem mesmo sistemas educacionais que já funcionam na sua capacidade máxima. Um modelo escolar ineficiente, insensível à realidade das comunidades que serve, pode ser parte da causa de seus próprios problemas. As crianças e suas famílias rejeitam escolas que não funcionam ou que não conseguem se encaixar em suas vidas as quais, em regiões pobres, são preenchidas com o trabalho necessário para sua sobrevivência. Por outro lado, uma reforma que ofereça educação aceitável para crianças que trabalham e que estavam excluídas do sistema, pode estar plantando as sementes de seu próprio sucesso. Será aprovada pelas crianças, pais e comunidades que encontrarão nela utilidade não só para seu futuro, como também para sua luta diária.

O título deste artigo coloca uma pergunta: "É possível conciliar educação com trabalho infantil"? É possível, sim, conforme explicado e ilustrado na discussão; e parece que acomodar uma coisa à outra poderia garantir benefícios substanciais tanto para as crianças quanto para a sociedade. Na verdade, à luz das diversas opções para conciliar trabalho com estudo na vida das crianças, pergunta-se como um modelo de política que enfatiza a separação das duas coisas conseguiu perdurar por tanto tempo nos países em desenvolvimento, onde parece estar cultural e economicamente fora de lugar. Estender uma educação significativa a todas as crianças, principalmente àquelas que vivem em áreas rurais e nas periferias pobres das cidades e que precisam passar parte de seu tempo trabalhando, exige que as escolas e outros programas educacionais se adaptem às realidades de suas vidas. Em muitos lugares, isso envolve necessariamente conciliar trabalho e estudo, para no mínimo algumas crianças. Este artigo demonstrou que isso é viável e, pelo menos em alguns casos, poder-se-ia esperar que também melhorasse a qualidade, atratividade e eficácia da educação. Existem mais do que razões suficientes para abandonar políticas baseadas na hipótese não-confirmada de que a 
educação e a maioria dos trabalhos infantis sejam incompatíveis entre si. Educadores e formuladores de políticas deveriam adotar uma perspectiva mais flexível que consiga imaginar o desenvolvimento humano como resultado da integração entre aprendizado e experiência e que cria políticas coerentes, oferecendo um tipo de educação que sirva de suporte na vida das crianças, como são no presente, assim como aquilo que podem vir a ser no futuro.

\section{REFERÊNCIAS BIBLIOGRÁFICAS}

21 st CENTURY LEARNING INITIATIVE. Schooling alone can not successfully prepare young people for the economic and social challenges of the 21' Century, 1997. [Faxed materials]

ABBOTT, J.; RYAN, T. The Unfinished revolution: learning, human behavior, community, and political paradox. Alexandria: ASCD, 2001.

AHMED, M. et al. Primary education for all: learning from the BRAC experience. Washington: Academy for Educational Development,1993.

BENEVOT, A. Educational expansion and economic growth in the modem world. In: FULLER, B.; RUBINSON, R. (eds.). The Political construction of education: the state, school expansion, and economic change. New York: Praeger, 1992.

BEQUELE, A.; MYERS, W. First things first in child labour. Geneva: ILO, 1995.

BOYDEN, J. The Relationship between education and child work. Occasional Paper 9. Florence: Unicef International Child Development Centre, 1994.

BOYDEN, J.; LING, B.; MYERS, W. What works for working children. Stockholm: Radda Bamen and Unicef International Child Development Centre, 1998.

COLE, M. Cultural psychology: a once and future discipline. Cambridge: Harvard University Press, 1996.

COLE, M.; COLE, S. The Development of children. 3.ed. New York: W.H. Freeman and Co., 1996. 
COSTA, A. C. G. da. Educação pelo trabalho. Belo Horizonte: Febem-MG, 1984.

CUNNINGHAM, H. Children of the poor: representations of childhood since the Seventeenth Century. Oxford: Blackwell, 1991.

The Decline of child labour: labour markets and family economies in Europe and North America since 1830. The Economic History Review, n.53, p.409-428, 2000.

FOSTER, P. J. The Vocational school fallacy in development planning. In: ANDERSON, C.A; BOWMAN, M. J. (eds.). Education and economic development. Chicago: Aldine, 1965.

FULLER, B. Growing-Up modern: the Western State builds third-world schools. London: Routledge, 1991.

GARDNER, H. Intelligence reframed: multiple intelligences for the 21' Century. New York: Basic Books, 1999.

. The Unschooled mind: how children think and how schools should teach. New York: Basic Books, 1991.

GUNN, S.; OSTOS, Z. Dilemmas in tackling child labour: the case of scavenger children in the Philippines. International Labour Review, n.131, p.629-646, 1992.

GUSTAFSSON, I. Schools and the transformation of work: a comparative study of four productive work programmes in Southern Africa. Stockholm: Institute of International Education, University of Stockholm, 1987.

HASPELS, N. et al. Action against child labour: strategies in education. International Programme for the Elimination of Child Labour. Geneva: ILO, 1999.

INTERNATIONAL LABOUR OFFICE. Conditions of work digest: the emerging response to child labour, v. 7, n.1, 1988.

INTERNATIONAL WORKING GROUP ON CHILD LABOUR. Working children: reconsidering the debates. Amsterdam: Defence for Children International, 1998.

KING, K. Aid and education in the developing world. Harlow: Longman, 1991. 
KRISHNA, S. Restoring childhood: learning, labour and gender in South Asia. Delhi: Konark Publishers, 1996.

LIEBEL, M. La Otra infancia: ninez trabajadora y accion social. Lima: Ifejant, 2000.

LIETEN, K. Children, work and education: economic and political weekly. Jun.10, p.2037-2043 and Jun.17, p.2171-2178, 2000.

A Note on child labour statistics and stereotypes. Paper for The IREWOC workshop on Children, Work and Education. Amsterdam, Nov., 15-17. 1999.

MINISTÉRIO DE PREVIDÊNCIA E ASSISTÊNCIA SOCIAL E UNICEF. Eu preciso trabalhar. Rio de Janeiro: MPAS e Unicef, 1983.

MYERS, W. Alternative services for street children: the Brazilian approach. In: BEQUELE, A.; BOYDEN, J. (eds.). Combating child labour. Geneva: ILO, 1988.

NARDINELLI, C. Child labour and the Industrial Revolution. Bloomington: Indiana University Press, 1990.

NIEUWENHUYS, O. Children's lifeworlds: gender, welfare and labour in the developing world. London: Routledge, 1994.

NUNES, T.; SCHLIEMANN, A. D.; CARRAHER, D.W. Street mathematics and school mathematics. Cambridge: Cambridge University Press, 1993.

PENNA, F. et al. The Generation and observation of evaluation indicators of the psychosocial development of participants in programmes for street children in Brazil. In: MYERS, W. (ed.) Protecting Working Children. London: Zed Books, 1991.

PERREAULT, G. Service learning. In:. GABBARD, D. A. (ed.) Knowledge and power in the global economy: politics and rhetoric of school reform. Mahwah, NJ: Lawrence Erlbaum, 2000.

POCZIK, R. Work-Based education and school reform. In: BAILEY, T. R. (ed.). Learning to work: employer involvement in school-to-work transition programs. Washington, D.C.: The Brookings Institution, 1995. 
RAMIREZ, F.; VENTRESCA, M. Building the institution of mass schooling: isomorphism in the modern world. In: FULLER, B.; RUBINSON, R. (eds.). The political construction of education: the state, school expansion, and economic change. New York: Praeger, 1992.

REIS, M. B. Projeto Axé. Brasília: ELO, 1993. [Unpublished report]

ROGOFF, B. Apprenticeship in thinking: cognitive development in social context. Oxford: Oxford University Press, 1990.

RUBINSON, R.; FULLER, B. Specifying the effects of education on national economic growth. In: FULLER, B.; RUBINSON, R. The Political construction of education: the state, school expansion, and economic change. New York: Praeger, 1992. p.101-115.

SCHIBOTTO, G. Niños trabajadores: construyendo una identidad. Lima: Manthoc, 1990.

SCHIEFELBEIN, E. School-Related economic incentives in Latin America: reducing drop-out and repetition and combating child labour. CRS 12, Innocenti Occasional Papers, Florence: Unicef International Child Development Centre, 1997.

SHEFFIELD, J. R., DIEJOMAOH, V. P. Non-Formal education in African development. New York: African-American Institute, 1972.

STERNBERG, R. J. Successful intelligence. New York: Plume, 1997.

SWIFT, A. Children for social change: education for citizenship of street and working children in Brazil. Nottingham: Educational Heretics Press, 1997.

Working children get organized: an introduction to working children's organizations. London: Save the Children, 1999.

TOLFREE, D. Old enough to work, old enough to have a say: different approaches to supporting working children. Stockholm: Radda Barnen, 1998.

UNESCO. Final report: International Conference on Education, $38^{\text {th }}$ session, Nov.10-19. Paris: Unesco, 1981.

. International meeting of experts on the promotion of productive work in education. Paris, Nov.24-28, 1980. 
UNICEF. Education and child labour: background paper for an international conference on child labour. Oslo, Oct. 27-30,1997.

. State of the world's children. New York, 1997a.

. State of the world's children. New York, 1999.

VALSINER, J. Culture and human development. Thousand Oaks: Sage, 2000.

WATKINS, K. Education now: break the cycle of poverty. Oxford: Oxfam, 1999.

WOOD, A.W. Informal education and development in Africa. The Hague: Mouton, 1974.

WOOD, D. How children think and learn. 2. ed. Oxford: Blackwell, 1998.

WOODHEAD, M. Children's perspectives on their working lives: a participatory study in Bangladesh, Ethiopia, The Philippines, Guatemala, El Salvador and Nicaragua. Stockholm: Rädda Barnen, 1998.

Is there a place for work, in child development?: implications of child development theory, and research for interpretation of the UN convention on the rights of the child, with particular reference to article 32, on children, work, and exploitation. Stockholm: Radda Barnen, 1999.

YATES, M.; YOUNISS, J. Roots of civic identity: international perspectives on community service and activism in youth. Cambridge: Cambridge University Press, 1999.

YOUNISS, J.; YATES, M. Community service and social responsibility in youth. Chicago: University of Chicago Press, 1997. 
